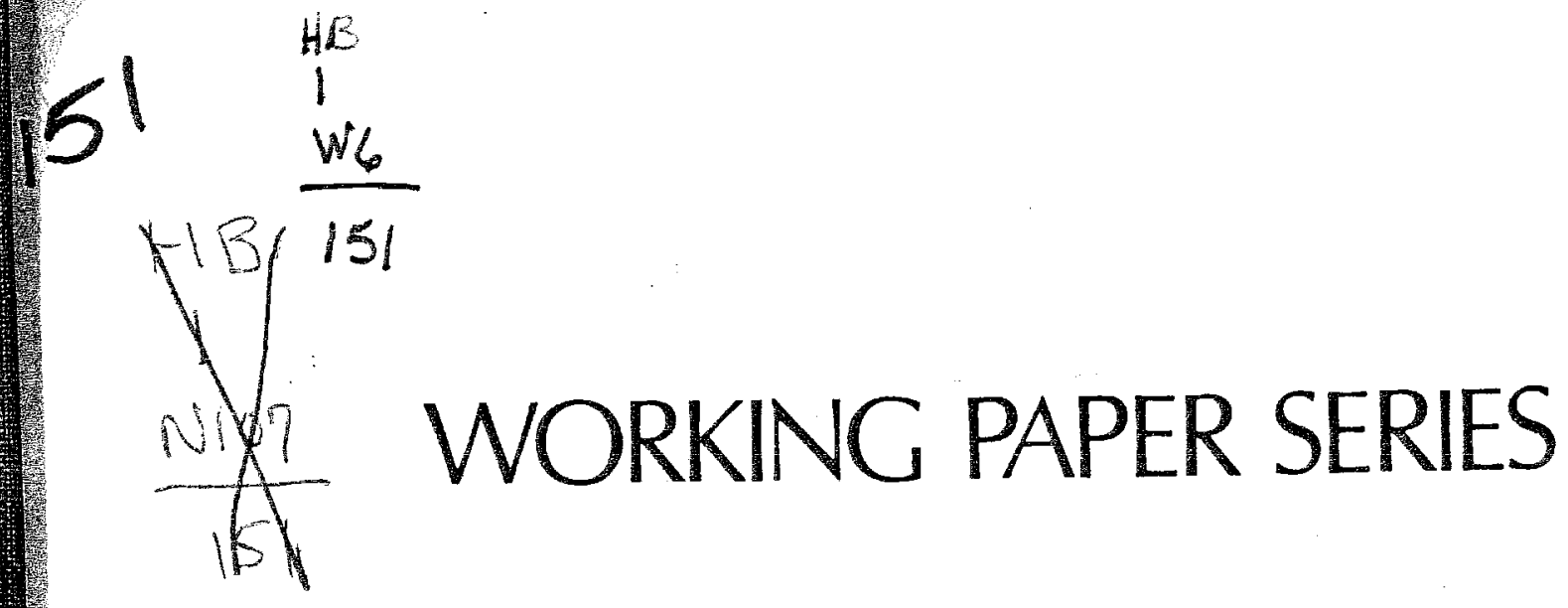

SOME LESSONS FROM THE NEW PUBLIC FINANCE

\author{
Joseph E. StIg1itz \\ Michael J. Boskin
}

Working Paper No. 151
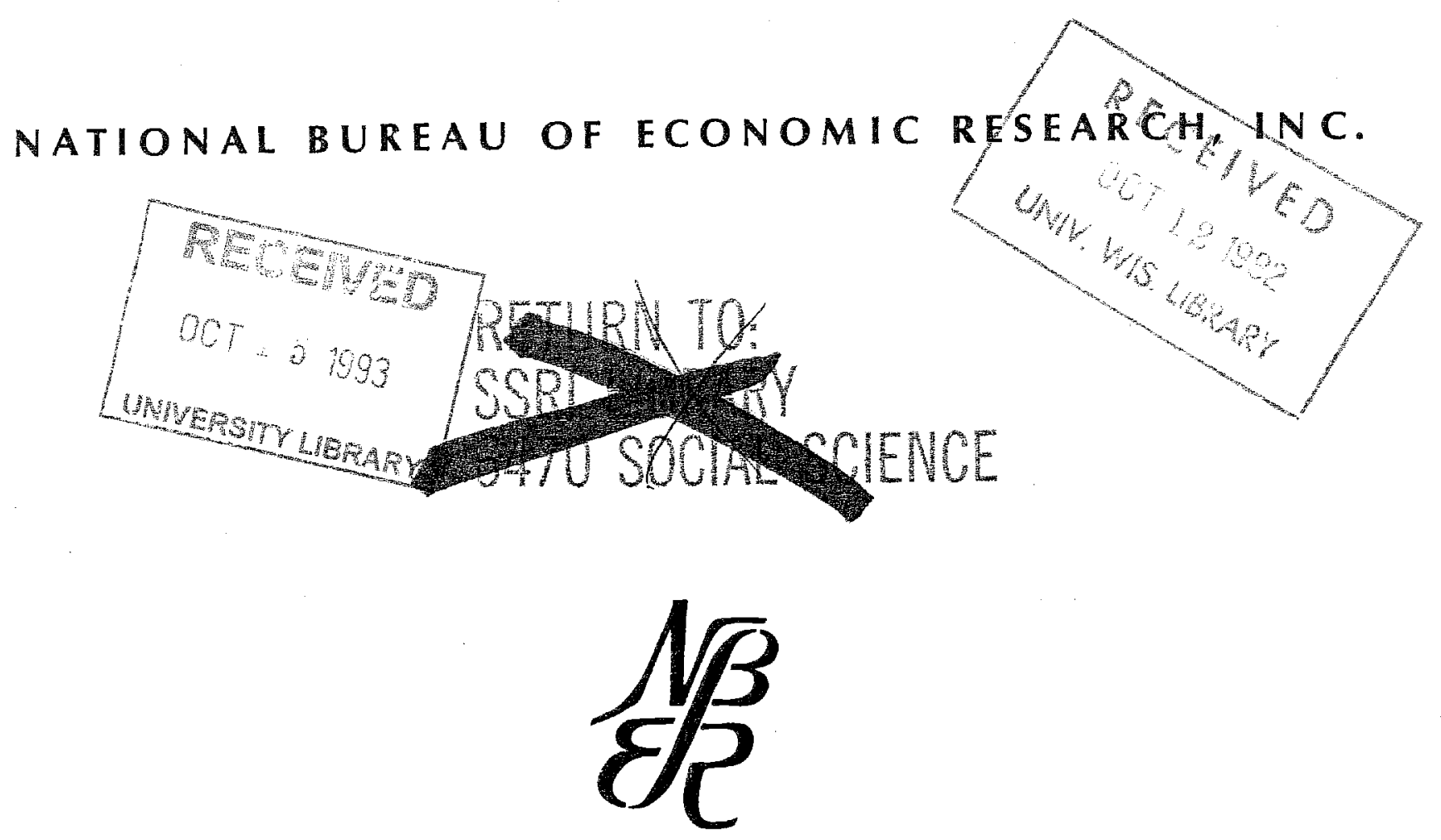


\section{SOME LESSONS FROM THE NEW PUBLIC FINANCE*}

\section{by}

Joseph E. Stiglitz** and Michael J. Boskin***

In the last few years, there has developed a large literature, sometimes referred to as the "new public finance," providing a quantitative analysis of a number of traditional problems within the field. This paper is concerned with surveying, or interpreting, what can be rearned from this literature; and our belief is that it has taught us a great deal. We concern ourselves here not so much with the derivation of precise formulae, e.g. for optimal tax rates, but with the more general lessons which have emerged. Some of these are of a philosophical sort -- how we ought to think about designing tax structures; some are of a negative sort -pointing out fallacies in traditional arguments or the lack of generality of previous results; finally, some are of a positive sort - deriving the conditions under which a particular tax structure or provision would be desirable. We shall present an example of each type of lesson in turn. Section $I$ discusses the philosophical basis of the new public finance. After discussing two strands of the recent literature, we conclude that the new approach is applicable to a wide range of problems in public finance and that it can and should supplant a variety of traditional ad hoc norms of a desirable tax structure.

*This paper was presented at the American Economic Association Meetings in Atlantic City, New Jersey, September 1976, where we received helpful advice from D. Bradford and M. Feldstein.

* Stanford University and Oxford University.

*** Stanford University and NBER. 
Section 2 analyzes perhaps the oldest question in public finance, the choice of an appropriate base of taxation. We discuss the conditions under which a consumption tax is desirable and the conditions under which other tax bases are desirable.

Section 3 offers a detailed analysis of special provisions in the tax laws by focusing on the tax treatment of medical expenditures. We demonstrate that under some conditions a deduction for medical expenditures, and under other conditions a tax creait, is desirable.

1. The Philosophic Basis of the New Public Economics

Two strands may be identified in the recent literature; the first is explicitly normative -- it takes some criterion, usually the utilitarian objective of maximizing the sum of utilities; makes some assumptions about the structure of the economy, including the set of instruments available to the government; and then derives from them some propositions concerning the optimal tax structure. I/ It explicitly recognizes the second (or third) best nature of the problems being discussed; indeed, this Iiterature probably represents the most significant body of work in "second best economics." This is important, because, as we shall show later, much common reasoning on tax problems is based on a misapplication of first best economics.

The problem of taxation in an economy such as ours is viewed as a problem of indirect control of imperfectly observable variables (see, for instance, Atkinson and Stiglitz [1976]); the government, for instance, might 
like to exempt "necessary" medical expenses, but finds it difficult (costly) to distinguish between these and "unnecessary" medical expenses; we might like to have an ability tax (which presumably would be non-distortionary), but we can only observe income, a compound of ability and effort; we might like to distinguish between wage and capital income in the unincorporated sector, but there is no obvious way of doing so; we might like to tax the output "automobile services" but it is much less expensive to monitor the inputs (gasoline and new cars).

This way of looking at tax problems is important because much of what otherwise might appear to be capricious, distortionary, or inequitable may at least make sense, and perhaps even be judged to be desirable.

The utilitarian framework has the advantage of providing a simple, unified, reasonably flexible ethical basis for judging among tax systems; for instance, by positing social welfare functions with different degrees of elasticity of substitution among the utilities of individuals, one can consider, at the one extreme, the Rawlsian criterion of maximizing the utility of the worst off individual; and at the other, the Benthamite criterion of adding up utilities. The traditional approach has involved "listing" criteria, e.g. horizontal equity, vertical equity, administrative costs, without providing any criterion for trading off among these objectives.

In fact, the principle of horizontal equity, at least as it has usually been formulated as equal tax treatment of equals (ex post equality, as opposed to ex ante equality, where they all have the same chances), is inconsistent with utilitarianism; i.e. in a wide variety of cases, maximizing 
the sum of (expected) utilities necessitates random taxation (Stiglitz [1976a]); as a practical matter, this might provide a justification for the random enforcement of taxes. It perhaps should be emphasized that this result is not an oddity: the conditions under which random taxation would be desirable are reasonably weak (e.g. with separable utility functions, all that is required is greater than unity risk aversion). The traditional "concavity argument, e.g. of Lerner and Samuelson (i.e. that because of diminishing marginal utility, social welfare is increased by equating incomes of people who are otherwise the same) fails in the context of the second best problems on which the new economics focuses.

The second strand in the literature is more positive in character. It shares with the first strand its concern for the general equilibrium analysis prevalent in the earlier literature and its emphasis on "distortionary" analysis -- its belief, or in the case of the empirical work, its verification -- that many of the relevant elasticities in the economy are far from zero (see Boskin [1977], Heckman [1974] and Feldstein [1975]). This is important: not only are the quantitative effects misjudged by assuming zero elasticities or ignoring general equilibrium effects, but the qualitative aspects of the desirable tax structure may be altered. For instance, an inheritance tax may well -- when the effects of the tax on saving, the effect of saving on the long run capital stock, and the effect of the capital stock on the distribution of incomes -- increase the degree of inequality in the wealth distribution rather than decrease it (Stiglitz [1966]); even apart from the capital accumulation effect it may 
increase the degree of inequality in consumption (Stiglitz [1976]); the social security system may similarly have adverse effects (Feldstein [1974]); the elimination of the provisions for charitable deduction may well decrease total expenditures on public type goods (Boskin [1976a] and Boskin and Feldstein [1977]).

The concern for the general equilibrium effects of a tax policy has led to the introduction or reemphasis of at least two concepts in assessing alternative programs. Stiglitz, arguing that, at least in many cases, the capital accumulation effects of a tax can be offset by government policy, has suggested the use of "balanced growth path incidence analysis" (Stiglitz [1976b]); in analogy to Musgrave's use of balanced budget analysis, the capital labor ratio, rather than national income or the budget, is held constant. Feldstein has, however, shown that the size of the effect of some programs, in particular social security, is so large that its effects cannot be offset by monetary, or other, policies affecting interest rates and national saving.

The other concept, the use of which is now written into law, is that of tax expenditures: the loss of revenue due to a particular provision. We have three major objections to this concept. First, as presently formulated, the measurement of forgone revenue implicitly assumes zero elasticities; the estimates of aggregate tax expenditures are only correct when one contemplates eliminating all deviations from taxing real economic income simultaneously and if the factors of production are in perfectly inelastic supply (which Boskin [1977] and Heckman [1974], among others, demonstrate is not the case). Further, the estimates for particular so-called tax 
preferences are often extremely inaccurate. For example, if the tax law allows a deduction for charitable contributions, it is not correct to argue that abolishing the deduction will increase tax revenue by (the sum over all contributors who itemize deduction) the product of the marginal tax rate and the amount currently given to charity. The amount of resources flowing into each such "tax expenditure" category reflects the tax treatment of that category as well as others. Since the charitable deduction reduces the price for a dollar of charitable contributions from $\$ 1$ to $\$(I-t)$, where $t$ is the marginal tax rate, any price elasticity at all in charitable giving would imply that abolishing the deduction would also reduce charitable contributions. Take the case of a family with a marginal tax rate of $20 \%$ which currently gives $\$ 300$ a year to charity. The tax expenditure budget counts 0.2 times $\$ 300$, or $\$ 60$, as a tax expenditure. Yet abolition of the deduction implies a $25 \%$ price increase; with the elasticity of -1.2 estimated by Feldstein [1976], contributions fall to $\$ 210$, and at the other extreme the "revenue foregone" is only $\$ 42$ if the extra $\$ 90$ does not flow into taxable income. The tax expenditure budget thus overestimates the revenue loss by more than forty percent! While it may not be inaccurate to argue that abolition of some preferences would increase taxable income by the amount now assumed in the tax expenditure budget, in many cases it is likely to be very inaccurate. For example, it would be heroic to assume that "full" taxation of capital gains would increase taxable income by anywhere near the tax expenditure budget's estimates. 
Second, as pointed out recently by Feldstein [1975b] government spending on an activity such as charity may decrease private spending on the commodity. The rationale for the tax expenditure budget is that the government could collect the foregone revenue and spend it on the "preferenced" commodity directly; it is obvious, however, that if each government dollar crowded out a private dollar, a non-zero pure substitution elasticity implies that the government would have to spend more than their estimated revenue loss to provide the equivalent total expenditure on the commodity. Third, the tax expenditure concept suffers from a further defect: the legislation implicitly assumed that the "natural" tax base is income, broadly defined; as we shall argue below, there is little justification for this. That is, to know what is being "exempted" from taxation one needs to know what "ought" to be taxed. By lising income defined in a broad way, the legislation focuses discussion on particular aspects of the tax code. (For instance, one might also argue that the failure to allow depreciation on human capital is a negative tax expenditure. See Boskin [1976b].)

The recent quantitative literature has also emphasized the importance of looking at the detailed structure of the tax code. For instance, because of the interest income exemption, the relevant marginal cost of capital for a corporation may be significantly different from the average cost; indeed, in the absence of uncertainty and with the appropriate depreciation provision, the corporation tax would be non-distortionary (equivalent to a pure profits tax); in some cases, the marginal cost of capital might even be less than the before tax rate of interest. (See Stiglitz [1973]). With true economic depreciation, a corporation tax without interest income exemption would 
also be non-distortionary (see Samuelson [1964]; for a summary, see Stiglitz [1975]). These aspects of the tax structure only become clear upon a detailed quantitative analysis.

\section{Choice of the Tax Base}

One of the most controversial issues in the literature on public finance is the choice of the tax base. The issue takes on a number of forms:

(a) The breadth of the tax base: should income be broadly defined, and special treatment of medical expenses, charity, etc. be eliminated?

(b) Consumption versus income: at least since Fisher, there has been widespread sentiment among academic economists that consumption provided a better base than income.

(c) Negative income tax versus specific subsidies (e.g. for food, housing, etc.). One of the contributions of the recent Iiterature (see Atkinson and Stiglitz [1976]) is its reemphasis that subsidies and taxes are really symmetrical, and therefore the question of the correct "subsidy base" is really the same as the question of the correct "tax base."

Much of the analysis of these issues -- that the consumption tax is desirable because it does not interfer with the intertemporal allocation of income (the marginal rate of substitution between consumption today and. tomorrow remains the same as the marginal rate of transformation) and that subsidies on food and housing are inefficient in distorting the allocation of expenditure among commodities -- is correct only under certain conditions; the argument that fewer distortions are better than more distortions is simply wrong. Faced with a seond-best problem, the use of first-best welfare 
economics may lead to seriously erroneous conclusions; a detailed analysis of the problem, taking account of the other distortions in the economy, is often necessary.

For example, Atkinson and Stiglitz have shown that if the utility function is separable between labor (leisure) and goods, if the source of inequality is in ability, and if the consumption tax is chosen optimally, then the consumption tax is the only tax to be imposed; there should be no commodity taxation and no taxation of interest income. If an optimal linear consumption tax is imposed, then this result holds only approximately, i.e. there should be "small" differential taxes or different commodities, which depend on third and higher derivatives of the utility functions.

However, when utility is not separable, a consumption tax is not the only desirable tax; but whether there should be a subsidy or a tax on interest income is a moot question; if we simplify the analysis by assuming a two period life cycle model, with individuals working and consuming the first period, and only consuming the second, with intertemporal separability in the utility function, then there should be an interest income subsidy (tax) if consumption and leisure are Edgeworth substitutes (complements).

These recent results thus not only cast doubt both on the generality of the analysis in favor of consumption taxes, and the significance of the earlier literature on optimal indirect taxation, in which only commodity taxation at constant rates (as opposed to progressive consumption or income taxes) was allowed, but point out the relevant empirical information (e.g. Whether utility is separable between leisure and goods) necessary to establish the desirable tax structure. 
Much recent empirical research has established a nonnegligible interest elasticity of saving and wage elasticity of labor supply (see Boskin [1977] and Hurd [1976]). Felstein has analyzed the desirability of consumption taxation in light of the empirical evidence and concludes that a decrease in capital income taxation is desirable.

\section{Special Provisions: Medical Allowances}

The provisions for deductability of certain expenses and tax credits for others may be analyzed within the same framework. A tax credit is equivalent to a proportional subsidy for the given good (at least for all individuals paying sufficient taxes), while deductability lowers the effective cost to individuals at a higher marginal bracket more than those at a lower marginal bracket.

The conventional wisdom on this is that deductability provisions are undesirable (relative to tax credits) because the differential prices paid by individuals result in a distortion, and that because the price is lowered more for the rich than for the poor, deductability provisions are inequitable. Neither argument is convincing: the first represents another misapplication of first best economics to a second best problem. The second assumes what is to be proven: what is the appropriate "equitable" tax base. One could equally well argue that the appropriate tax base is real income, and that nominal income minus medical expenses is a better proxy for real income than nominal income alone. In that case, there is a presumption for tax deductability, rather than for a tax credit.

In the analysis referred to in section 2 , individuals differed only with respect to their earning capacity. If that were the case, then neither 
tax deductability nor a tax credit would be desirable (under the assumption of separability). The argument then for either must be based on a recognitio of individual differences with respect to medical needs, and a belief that an ideal tax system (a perfect screening system) would differentiate the tax burden on people with different medical situations. The argument may be put in either ability to pay or utilitarian terms: that necessary medical expens are a subtraction from the individual's ability to contribute to the support government services or that they raise the marginal utility of income (since represent a subtraction from "enjoyable consumption). An ideal tax system would thus relate taxes to ability, A, and health needs:

$$
T^{*}=T(A, H)
$$

where $H$ is health, with $T_{H}<0$. But neither $A$ nor $H$ is easily observable. We shall analyze the desirability of the alternative programs within the utilitarian framework. A similar analysis could be made for a variety of other special tax provisions.

Assume that the demand for medical services of any given individual is perfectly inelastic; a particular amount is required just to survive; any amount beyond that has zero utility. Differences in these required medical expenses are the only way in which individuals differ with respect to $H$. Then medical expenses would be a perfect surrogate for $H$. If we assume that the individual's indirect utility function can be written in the form

$$
V(p, I-H)
$$


then the appropriate tax treatment would be to give a $100 \%$ tax credit, assuming $\mathrm{H}, I$, and $A$ are uncorrelated, and assuming that the government can impose a uniform Iump sum tax (subsidy).

In the realistic case, the demand for health is not completely inelastic, (see Feldstein [1974a]) so that actual expenditures are only a surrogate for medical needs. But it has an even more important implication: allowing a full credit would obviously be extremely distortionary, leading all individuals to demand medical services up to the point of satiation. Thus, any tax system must allow for only partial payment by the government of medical expenses.

Indeed, we can view the tax deductability provision as a form of partial insurance for medical expenses; the partial nature of the insurance arises from the same kinds of considerations which lead to co-insurance in conventional insurance policies -- moral hazard. Individuals in different income brackets are, however, offered different insurance policies, and an insurance policy with a nonconstant co-insurance provision. To the extent that they face the same risks (in dollar equivalent terms), have the same demand elasticities, and have the same relative risk aversion, since the risks are smaller relative to income (wealth) for the wealthier, the return to having the insurance is smaller while the deadweight loss is the same, leading to some presumption for the wealthier to have less insurance, i.e. the government should allow them a lower tax credit rate (a lower percentage of their medical expenses being deductable). Moreover, if there is diminishing marginal utility of consumption of nonmedical goods, then it would seem desirable to have a larger fraction of large medical expenses insured than 
of small medical expenses. The tax deductability provision works in just the opposite way, providing smaller marginal co-insurance rates (for a given income) as expenses go up. This provides some further argument agains deductability over a tax credit.

Income may respond to health needs as well; to compensate for greater medical needs, an individual may be induced to work harder, in which case higher incomes do not represent higher levels of "enjoyment," but only greater needs. In that case, deductability is preferable to a credit, since income net of medical expenses is clearly a better measure of welfare than just income alone. $\frac{3 /}{}$

This is illustrated by the following simple model. Let the utility function be

$$
W=U(C)+Z(M, H)-V L
$$

where $C$ is "effective" consumption, $M$ is medical expenditures, $H$ is health, and $I$ is labor supplied. $z$ represents the "direct" utility of medical expenditures.

In general, effective consumption will be a function of health, income, and expenditures on medical care. One simple specification is 4

$$
C=(I-M)+(M-H)
$$

C equals expenditure on non-medical items, plus all expenditures on medicine in excess of health needs, H. For simplicity, assume I consists of only labor income minus tax payments,

$$
I=W L-T\left(W L-\lambda_{I} M\right)+\lambda_{2} M
$$




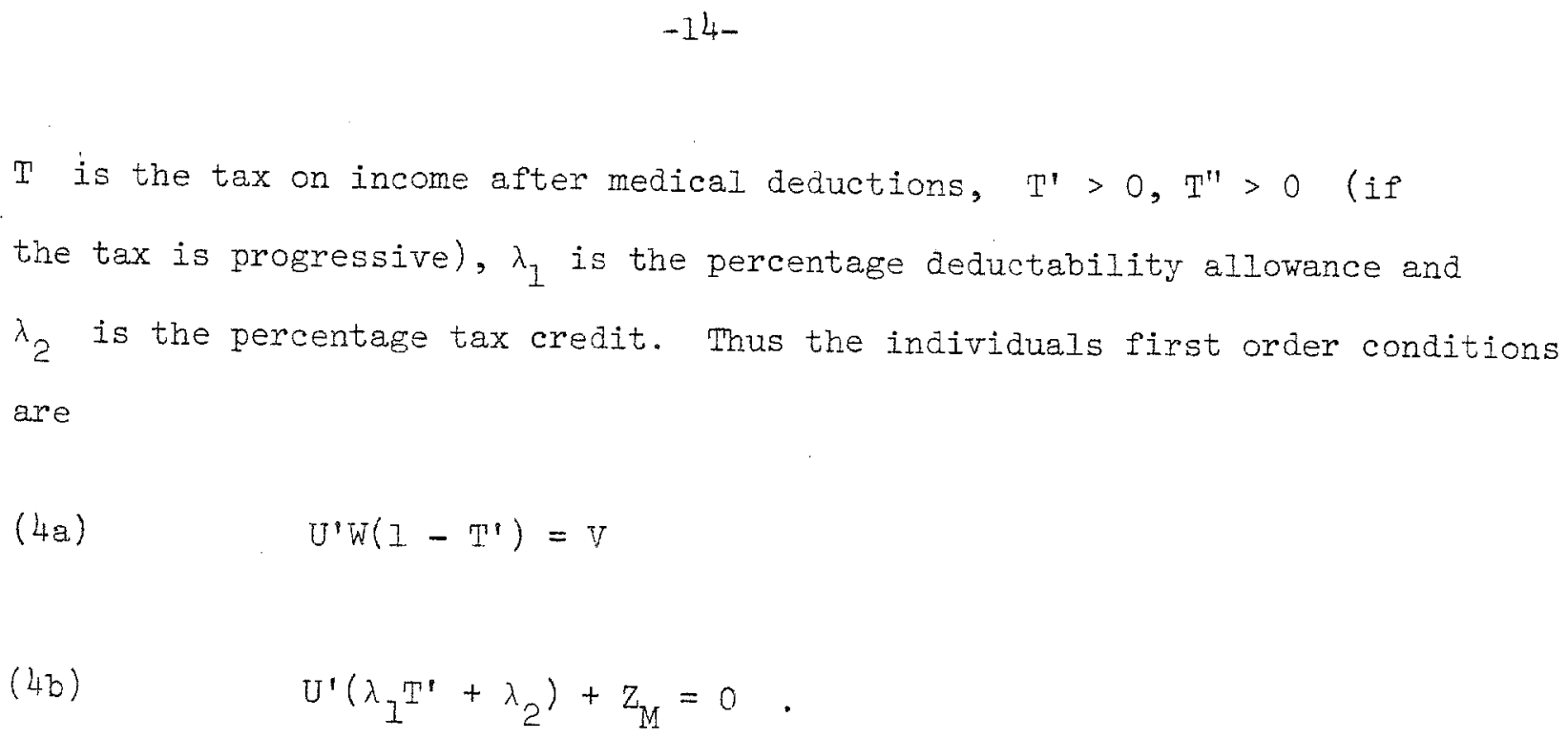

The government wishes to choose $\lambda_{1}$ and $\lambda_{2}$, the percentage deduction and credit allowances, to maximize

$$
\int W(W, H) d F(W, H)
$$

(where $F$ is the distribution function of individuals by wage rates (ability) and health needs $(H)$ ) subject to

$$
R=\int\left[T\left(I-\lambda_{I} M\right)-\lambda_{2} M\right] d f
$$

We thus obtain (letting $\mu$ be the Lagrangian multiplier associated with (6))

$$
\int M\left[U ^ { \prime } - \mu ( I - \frac { S } { I - S } \varepsilon ) d F ^ { \prime } \leq 0 \text { as } \left\{\begin{array}{l}
\lambda_{2}=0 \\
0 \leq \lambda_{2} \leq 1 \\
\lambda_{2}=1
\end{array}\right.\right.
$$

$$
\int T^{\prime} M\left[U ^ { \prime } - \mu ( I - \frac { S } { I - S } \varepsilon ) d F \leq 0 \text { as } \left\{\begin{array}{l}
\lambda_{I}=1 \\
0 \leq \lambda_{I} \leq 1 \\
\lambda_{I}=0
\end{array}\right.\right.
$$


where $\varepsilon$ is the price elasticity of the demand for medicine and where $S$ is the marginal subsidy rate. Straightforward calculations establish that (provided $z_{M H}>0$ ) if $\lambda_{1}=0$

$$
\frac{\partial C}{\partial H}<0, \frac{\partial M}{\partial H}>0, \frac{d I}{d H}>0
$$

Increasing health needs increases medical expenditures and lowers effective consumption.

If the only source of variability in $M$ arose from variations in health needs, $H$, then it is easy to establish (assuming the price elasticity does not increase with health needs) either only tax deductability should be allowed or both a credit and deductability should be employed, but a tax credit should never be used alone. $5 /$

If, on the other hand, labor is inelastically supplied ( $I$ is fixed), equations (7) and (8) remain unaffected; but now, if $H$ is the only source of variability, then a deductability provision should never be used (except if a full credit $\left(\lambda_{2}=1\right)$ is used in addition, which, since this is equivalent to giving $M$ away, it never will be). $6 /$

Thus, whether the insurance considerations or equity considerations dominate depends on the responsiveness of income to health considerations.

Even this analysis, we suspect, overstates the case for the desirability of a tax credit. Assume that different individuals had inelastic demands for medical care, but that their demands were only partially correlated with true health needs. Assume $M$ and $H$ are jointly normally distributeã, with correlation coefficient $\rho$, which is independent of $I$. Assume a social welfare function of the form 


$$
W=\int[U(I-H-T(M, I)) d F
$$

where $F$ is the distribution function of individuals over $H, I$, and $M$, and where $T(M, I)$ is the tax function which we assume to be of the form $T=T\left(I-\lambda_{I} M\right)-\lambda_{2} M$. In particular, we assume $U$ is quadratic. Then it is easy to show maximizing social welfare requires a deduction from income of an amount $\zeta M$. 


\section{Footnotes}

If See, for example, Baumol and Bradford [1970], Diamond and Mirrlees [1971], Harberger [1964], and Atkinson and Stiglitz [1972].

2/ In this case, equivalent to immediate write off of the investment.

3/ We are concerned here less with the exhaustive treatment of a particular item, or even the realism of the model, than with demonstrating that a variety of considerations enter the choice between credit and deduction; and that these may be analyzed in the utilitarian framework.

4/ Other specifications, e.g. C = I - M, yield similar results.

2) Assume $\lambda_{1}=0$. Then when ( 8 ; is non-positive, (7) is negative.

6/ When (8) equals zero, (7) is positive; this follows upon observing that

$$
\frac{d U^{\prime}}{d H}=-U^{\prime \prime}\left(I-T^{\prime} \lambda_{I} \frac{d M}{d H}\right)>0
$$

(provided the tax savings induced by increased medical expenditures exceed the price of medical services), and $d T^{1} / d H<0, d S / d H<0$. 


\section{References}

Atkinson, A. and J. Stiglitz [1976], "The Design of Tax Structure: Direct Versus Indirect Taxation," Journal of Public Economics 6, pp. 55-75. Baumol, W. and D. Bradford [1970], "Optimal Departures from Marginal Cost
Pricing," American Economic Review, June.

Boskin, M. [1977], "Taxatior, Saving and the Rate of Interest," JPE,
forthcoming.

Boskin, M. [1976a], "Estate Taxation and Charitable Bequests," Journal
of Public Economics.

Boskin, M. [1976b], "Notes on the Tax Treatment of Human Capital," Treasury Conference on Tax Research, forthcoming.

Boskin, M. and M. Feldstein [1977], "The Effects of the Charitable Deduction on Contributions by Low and Midale Income Households," Review of
Economics and Statistics, forthcoming.

Diamond, P. and J. Mirrlees [1971], "Optimal Taxation and Public Production: I and II," American Ecoromic Review, Marc h and June.

Feldstein, M. [1975a], "The Effects of the Charitable Deduction on Contributions: I. and II.," National Tax Journal.

Feldstein, M. [19750], "The Theory of Tax Expenditures," HIER Discussion Papaer.

Feldstein, M. [1974a], "The Welfare Costs of Health Insurance," JPE.

Feldstein, M. [1974b], "Social Security, Induced Retirement, and Aggregate Capital Accumulation," JPE.

Harberger, A. [1964], "Taxation, Resource Allocation and Welfare," in J. Due (ed.) The Role of Direct and Indirect Taxes In the Federal Revenue System, NBER. Heckman, J. [1974], "Shadow Prices, Market Wages and Female Labor Supply,"
Econometrica.

Samuelson, P. [1964], "Tax Deductability of Economic Depreciation to Insure Invariant Valuations," Journal of Political Economy,
$72, \mathrm{pp} .604-606$.

Stiglitz, J. [1976a], "Utilitarianism and Horizontal Equity: The Case for Random Taxation," IMSSS Technical Report No. 214, Stanford University. 
Stiglitz, J. [1976b], "Estate Taxes, Growth and Redistribution," in R. Grieson ed., Essays in Honor of W. Vickrey.

Stiglitz, J. [1975], "The Corporation Tax," Journal of Public Economics 5.

Stiglitz, J. [1973], "Taxation, Corporate Financial Policy, and the Cost of Capital," Journal of Public Economics, pp. 1 - 34.

Stiglitz, J. [1966], "The Distribution of Income and Wealth Among Individuals," Econometrica, July 1969, pp. 382-397, (presented at the December 1966 meetings of the Econometric Society, San Francisco. 